\title{
High intensity focused ultrasound (HIFU) in the treatment of breast fibroadenomata: a feasibility study
}

\author{
Mirjam Peek ${ }^{1 *}$, Muneer Ahmed ${ }^{1}$, Julie Scudder ${ }^{1}$, Arnie Purushotham', Ashutosh Kothari ${ }^{2}$, Hamed Hisham², \\ Tibor Kovacs², Sarah McWilliams², Sarah Pinder ${ }^{2}$, Bennie ten Haken ${ }^{3}$, Michael Douek ${ }^{1}$ \\ From Current and Future Applications of Focused Ultrasound 2014. 4th International Symposium \\ Washington, D.C, USA. 12-16 October 2014
}

\section{Background/introduction}

Breast fibroadenomata (FAD) are the most common breast lesions in woman. For palpable lesions, three options are available: reassurance (with or without follow-up), vacuum assisted mammotome (VAM) or surgical excision. High intensity focused ultrasound (HIFU) is a non-invasive ablative technique in which an ultrasound (US) beam propagates through tissue as a high-frequency pressure wave and is focused onto targeted tissue which elevates the temperature of the focused area without causing damage to the adjacent tissues. HIFU is normally applied to the whole lesion. In this trial, we performed circumferential HIFU treatment to isolate the fibroadenoma from its blood supply. Primary end points of this trial included the decrease in treatment time and shortterm complication rate.

\section{Methods}

Patients (age $\geq 18$ years) were recruited with symptomatic fibroadenomata which had to be visible on US (grade U2/U3). In patients older than 25 years, a fine needle aspiration cytology (FNAC) or core needle biopsy (CNB) was performed to confirm the diagnosis of a FAD. Patients were treated using the US guided - THone Echopulse device (Theraclion, France) under local anaesthesia (1:1, 1\% Lignocaine with adrenaline and $0.25-0.50 \%$ Chirocaine).

\section{Results and conclusions}

From December 2013, 13 patients with symptomatic fibroadenomata underwent circumferential HIFU treatment. Seven patients opted for HIFU treatment due to pain or discomfort. Average treatment time for approximately 61 sonications (SD, 17 sonications), was 36 minutes (SD, 12 minutes). Circumferential treatment reduced treatment time by an average of $44 \%$ (SD, 21\%). A two-sample $T$-test assuming unequal variances showed a significant reduction in treatment time $(\mathrm{P}=$ 0.005, two-tailed).

Post-treatment follow-up at 2 weeks showed reduced pain in six out of seven patients with resolution of pain in three of these. An additional patient developed new pain after two weeks. Short-term complications were erythema of the skin $(n=4)$, ecchymosis $(n=4)$, temporarily numbness of the skin $(n=1)$ and a first-degree skin burn $(n=1)$.

Circumferential HIFU ablation of fibroadenomata is feasible with a significant reduction in treatment time.

\section{Acknowledgements (Funding) \\ Educational grant from Theraclion, Paris, France.}

\section{Authors' details}

'King's College London, London, United Kingdom. ' $G u y$ 's and St. Thomas', London, United Kingdom. ${ }^{3}$ University of Twente, Enschede, Netherlands.

Published: 30 June 2015

\section{doi:10.1186/2050-5736-3-S1-077}

Cite this article as: Peek et al:: High intensity focused ultrasound (HIFU)

in the treatment of breast fibroadenomata: a feasibility study. Journal of

Therapeutic Ultrasound 2015 3(Suppl 1):077.

King's College London, London, United Kingdom

Full list of author information is available at the end of the article 